\title{
MENISCAL REPAIR RESULTS COMPARING MRI, ARTHRO-MRI, AND ARTHRO-CT
}

\section{RESULTADOS DA SUTURA MENISCAL COMPARANDO RM, ARTRO-RM E ARTRO-CT}

\author{
Adriano Marques de Almeida ${ }^{1}$, Marcelo Bordalo Rodrigues ${ }^{1}$, Marcia Uchôa de Rezende ${ }^{1}$, André Pedrinelli ${ }^{1}$, Arnaldo José Hernandez ${ }^{1}$ \\ 1. University of São Paulo, Department of Orthopedics and Traumatology, FIFA Medical Center of Excellence, São Paulo, SP, Brazil.
}

\section{ABSTRACT}

Objective: To clinically and radiologically evaluate patients who received meniscal suture using the outside-in technique, comparing magnetic resonance imaging (MRI), arthro-magnetic resonance imaging (arthro-MRI), and arthro-computed tomography (arthro-CT) to evaluate the healing of meniscal sutures. Methods: We evaluated eight patients with an average follow-up of 15 months. The evaluation analyzed clinical parameters using the Lysholm and IKDC scores as well as MRI, arthro-MRI, and arthro-CT imaging. Results: At the end of the follow-up period, mean Lysholm score was 89.5 and mean IKDC score was 78.6. In the MRI, signs of meniscal healing were observed in $50 \%$ of the cases. The arthro-MRI and arthro-CT showed signs of healing in $75 \%$ of cases. There was a positive correlation between arthro-MRI and arthro-CT results in all the cases studied (kappa correlation index=1). Conclusion: Meniscal suture using the outside-in technique presented good or excellent results in $87.5 \%$ of our patients. The arthro-CT and arthro-MRI showed the same level of accuracy in detecting healing of the sutured region of the meniscus. Level of Evidence IV; Case series.

Keywords: Meniscus. Knee. Magnetic resonance imaging. Tomography.

\section{RESUMO}

Objetivo: Avaliar clinicamente e radiologicamente pacientes submetidos a sutura-meniscal pela técnica outside-in, comparando a Ressonância Magnética (RM), Artro-Ressonância Magnética (Artro-RM) e Artro-Tomografia Computadorizada (Artro-CT), quanto a cicatrização da sutura meniscal. Método: Avaliamos oito pacientes com um seguimento médio de 15 meses, clinicamente e por meio de score de Lisholm e IKDC, e realizamos RM, Artro-RM e Artro-CT. Resultados: A média do score de Lysholm foi de 89.5 e o score médio do IKDC foi de 78,6. A RNM observou sinais de cicatrização meniscal em $50 \%$ dos casos, enquanto a artro-RNM e artro-CT evidenciaram sinais de cicatrização em 75\% dos casos. Houve uma correlação entre a artro-RNM e a artro-CT em todos os casos. Conclusão: A sutura meniscal pela técnica outside-in apresentou bons e excelentes resultados em 87,5\% dos nossos pacientes. A artro-CT e a artro-RNM têm acurácia equivalente na detecção da cicatrização da região suturada do menisco. Nível de Evidência IV; Série de casos.

Descritores: Menisco. Joelho. Imagem por ressonância magnética. Tomografia.

Citation: Almeida AM, Rodrigues MB, Rezende MU, Pedrinelli A, Hernandez AJ. Meniscal repair results comparing mri, arthro-mri, and arthro-ct. Acta Ortop Bras. [online]. 2018;26(3):166-9. Available from URL: http://www.scielo.br/aob.

\section{INTRODUCTION}

Formerly considered vestigial structures, ${ }^{1}$ the menisci are now recognized as vital structures for the biomechanics and integrity of the joint surface of the knee. The known functions of the meniscus include increased femoral tibial joint congruence, joint stability, distribution of the synovial fluid and reduced friction between the joint surfaces, and increased surface area of contact between the femur and the tibia. These factors help reduce contact pressure between the surfaces of the joint, and have a positive effect on joint proprioception.

Despite the satisfactory initial results of meniscectomy for the treatment of patients with meniscal lesion, it was soon observed that this procedure is not without its drawbacks. According to Fairbank, ${ }^{2}$ in patients who have undergone meniscectomy, degenerative alterations occur in the joint cartilage of the knee in direct proportion to the quantity of dried meniscus. A knowledge of the function and importance of the meniscus has led to greater emphasis on its preservation, through partial meniscectomies and techniques for repairing the torn meniscus.

The use of techniques to repair the torn meniscus through the use of sutures has been described as far back as the end of the 19th century, ${ }^{3}$ with studies on animals from the 1930 s. ${ }^{4}$ However, the rational use of meniscal suture came with subsequent studies on vascularization of the meniscus. Arnoczky and Warren ${ }^{1}$ demonstrated,

All authors declare no potential conflict of interest related to this article.

Work conducted at the Department of Orthopedics and traumatology at the FIFA Center of Excellence, Hospital das Clinicas, Faculdade de Medicina da Universidade de São Paulo, São Paulo, SP, Brazil.

Correspondence: Rua Dr. Ovídio Pires de Campos, 333, Cerqueira Cesar, São Paulo, SP, Brazil. 05403-010. adrianoalmeida@usp.br 
in human corpses, the presence of capillary plexuses covering up to $30 \%$ of the meniscus, from its more peripheral portion, inferring the capacity to heal lesions situated in this region. The development of the surgical technique, particularly through arthroscopy, made suture of the meniscus a viable, low risk procedure, which led to a more biological practice with the focus on preserving the meniscus. Various techniques are currently used for meniscal suture. ${ }^{5}$ The most common of these is the outside-in technique. ${ }^{6}$ Previous studies have demonstrated good or excellent results in more than $90 \%$ of patients, using this technique.,

The objective of this study is to clinically and radiologically evaluate the result of meniscal suture in these patients. The purpose of the radiological study is to evaluate the healing of meniscal lesions after suture, through Magnetic Resonance Imaging (MRI) without contrast medium, or with intrajoint contrast medium (Arthro-MRI), and through Computed Tomography with intrajoint contrast medium (Arthro-CT).

\section{MATERIALS AND METHODS}

The study was approved by the institutional review board, protocol (number 806/06), and all individuals were informed about the research purposes and signed written informed consent. We evaluated eight patients submitted to meniscal repair. All patients were male, with an average age of 33.5 years old (range 20 to 48 years old). Meniscus repair was performed by the outside-in technique, with an average follow-up of 40.2 months. (Table 1) The lesion was located in the medial meniscus in all cases. Five patients presented associated lesion of the anterior cruciate ligament, and reconstruction was carried out concomitantly, using autologous patellar tendon graft.

\section{Surgical technique}

The outside-in technique was used for the meniscal repair. Before starting the suture, we removed the debris from the edges of the meniscal lesion with a shaver, to promote healing. Next, we took an absorbable suture thread (vicryl $\left.{ }^{\circledR} \mathrm{n}^{0} 1\right)$ and passed it with a 14 gauge needle from outside to inside through a small incision on the medial side of the knee, perforating the meniscus and the adjacent joint capsule, and going right through the lesion. The suture thread was retrieved from the arthroscopic portal with a grasper. In the same way, we inserted another suture thread approximately $5 \mathrm{~mm}$ from the first, tied them outside the portal and retrieved the knot from the medial incision. Then we tied the knot in the capsule, repairing the meniscus to the joint capsule.

In the postoperative program, we emphasized the recovery of muscular strength, total extension, and flexion of up to $90^{\circ}$ in the first month. We did not restrict weight-bearing.

Table 1. demographic data of the patients.

\begin{tabular}{c|c|c|c|c|c}
\hline Patient & $\begin{array}{c}\text { Age } \\
\text { (years) }\end{array}$ & $\begin{array}{c}\text { Time } \\
\text { (months) }\end{array}$ & $\begin{array}{c}\text { Associa- } \\
\text { ted injury }\end{array}$ & Meniscus & Side \\
\hline ESPV & 20 & 24 & None & Medial & $\mathrm{R}$ \\
\hline RTA & 28 & 6 & ACL & Medial & $\mathrm{L}$ \\
\hline AICA & 36 & 7 & ACL & Medial & $\mathrm{R}$ \\
\hline DMA & 20 & 12 & ACL & Medial & $\mathrm{R}$ \\
\hline MAD & 33 & 7 & ACL & Medial & $\mathrm{R}$ \\
\hline MAFL & 29 & 24 & None & Medial & $\mathrm{R}$ \\
\hline LAPJ & 21 & 36 & ACL & Medial & $\mathrm{L}$ \\
\hline FES & 48 & 14 & None & Medial & $\mathrm{R}$ \\
\hline
\end{tabular}

The patients were evaluated in relation to range of movement, swelling of the joint, crepitation, stability, muscular atrophy, presence of pain in the joint interline, and the McMurray test. The patients were questioned about their level of sports activity compared with before the lesion, and their return to work.

The patients with normal results in the clinical examination, without any complaints about the repaired knee, and who returned to unrestricted activities, were classified as excellent. Patients with pain or swelling in the joint, but without mechanical symptoms and with normal results in the clinical examination were classified as good. Those with persistent pain, swelling of the joint and mechanical symptoms were classified as failures. The patients responded to the Lysholm ${ }^{9}$ and subjective IKDC ${ }^{10}$ questionnaires.

We carried out the imaging exams on all the patients, who were submitted to Magnetic Nuclear Resonance Imaging (MRI) without contrast or with intrajoint contrast medium (Arthro-RMI), and through Computed Tomography with intrajoint contrast (Arthro-CT). A gadolinium solution (paramagnetic contrast) was used, and non-ionic iodine, administered in the joint by the radiologist, just before the examination. The images were evaluated and drawn up in reports by one of the authors (MBR), a radiologist who specializes in the musculoskeletal system.

\section{RESULTS}

Based on the previously established criteria, seven cases were classified as excellent, and one as good. None of the cases were clinically classified as a failure. Mean Lysholm score was 89.5 and mean IKDC score was 78.6. (Table 2) In relation to the physical examination, all the patients presented complete recovery of the range of movement, and a negative result in the McMurray test. All the patients returned to work, and five patients resumed sports without limitations.

Signs of meniscal healing were observed in $50 \%$ of the cases in the MRI, characterized by the absence of hypersignal in the meniscus in T2 sequences. The arthro-MRI and arthro-CT showed signs of healing in $75 \%$ of the cases, as characterized by the absence of penetration of the contrast medium in the meniscus. (Figures 1 and 2) There was a correlation between the arthro-MRI and the arthro-CT in all the cases (kappa correlation index=1).

\section{DISCUSSION}

The success of the meniscal repair is directly related to the indication. We indicate repair in cases of longitudinal, peripheral lesions, within the red zone, preferably severe. However, if the lesion is favorable, we indicate suture, even in chronic cases. When associated with lesion of the ACL, concomitant ligament reconstruction appears to promote healing of the meniscus. ${ }^{11-14}$ This was the conduct adopted

Table 2. Lysholm scores ( $E=$ excellent, $G=$ good, $R=$ regular), IKDC score and meniscus healed $(\mathrm{H})$ or not healed $(\mathrm{N})$.

\begin{tabular}{c|c|c|c|c|c}
\hline Patient & Lysholm score & $\begin{array}{c}\text { IKDC } \\
\text { Score }\end{array}$ & MRI & Arthro-MRI & Arthro-CT \\
\hline ESPV & $94(\mathrm{E})$ & 86 & $\mathrm{H}$ & $\mathrm{H}$ & $\mathrm{H}$ \\
\hline RTA & $90(\mathrm{G})$ & 80 & $\mathrm{~N}$ & $\mathrm{~N}$ & $\mathrm{~N}$ \\
\hline AICA & $89(\mathrm{G})$ & 69 & $\mathrm{~N}$ & $\mathrm{H}$ & $\mathrm{H}$ \\
\hline DMA & $95(\mathrm{E})$ & 89 & $\mathrm{~N}$ & $\mathrm{H}$ & $\mathrm{H}$ \\
\hline MAD & $94(\mathrm{E})$ & 86 & $\mathrm{H}$ & $\mathrm{H}$ & $\mathrm{H}$ \\
\hline MAFL & $90(\mathrm{G})$ & 68 & $\mathrm{~N}$ & $\mathrm{~N}$ & $\mathrm{~N}$ \\
\hline LAPJ & $65(\mathrm{R})$ & 62 & $\mathrm{H}$ & $\mathrm{H}$ & $\mathrm{H}$ \\
\hline FES & $99(\mathrm{E})$ & 89 & $\mathrm{H}$ & $\mathrm{H}$ & $\mathrm{H}$ \\
\hline
\end{tabular}




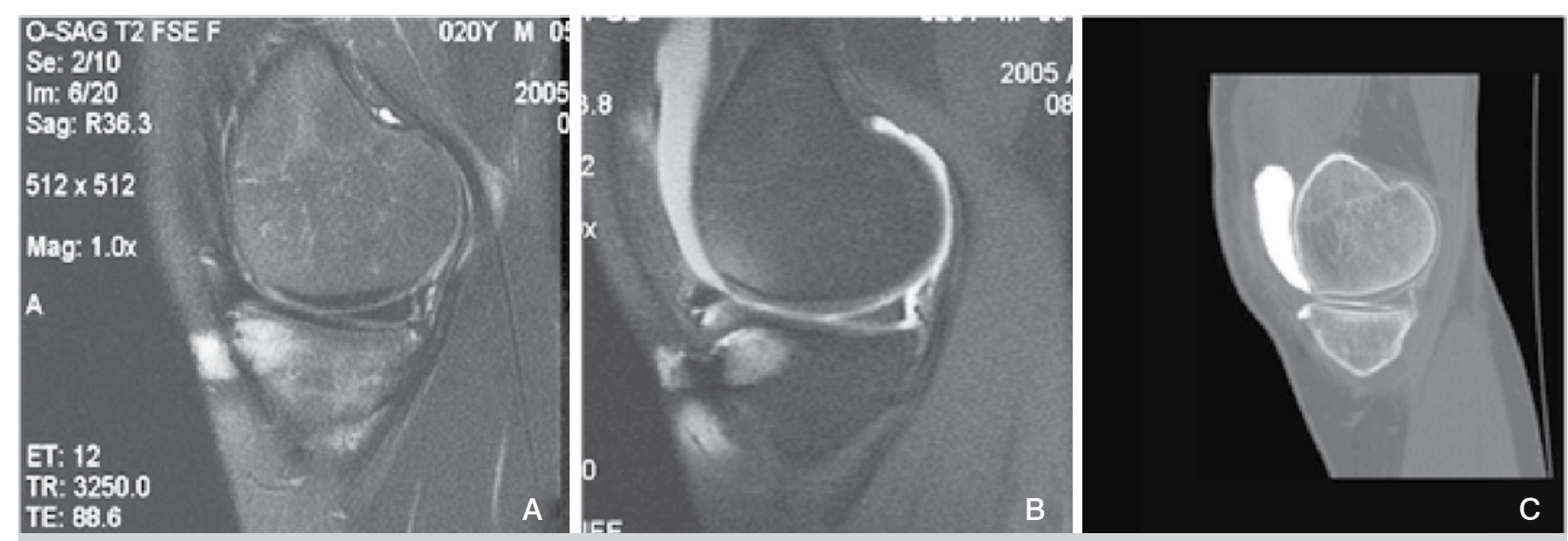

Figure 1. Knee MRI, Arhro-MRI and Arthro-CT after meniscal suture. See the hypersignal in T2 (left) and the penetration of the contrast medium (middle and right pictures).
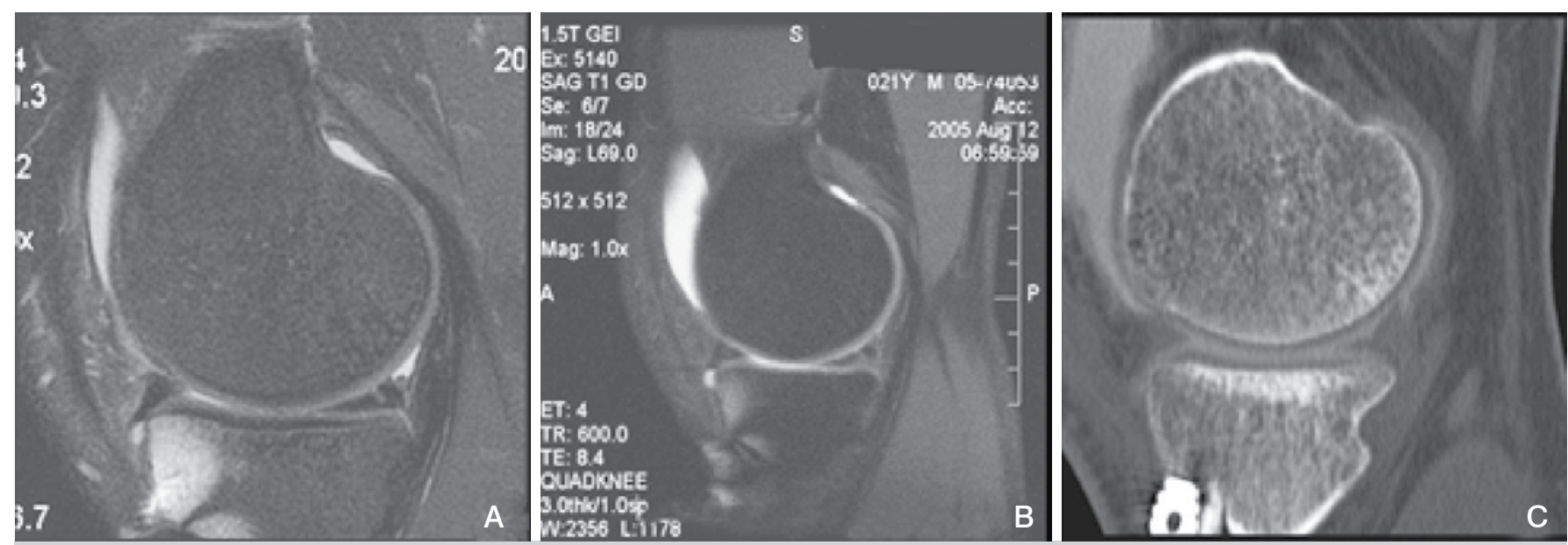

Figure 2. Hypersignal of the posterior horn of the meniscus (left) in the MRI and absence of penetration of contrast medium (middle and right pictures).

in our patients with unstable knees. Although the small number of patients did not enable any statistically significant conclusion to be drawn in this regard, we observed no differences between the patients with stable knees, and those who underwent reconstruction of the ACL.

The rate of good and excellent results obtained in our study (87.5\%) is in accordance with the data reported in the literature. ${ }^{7,8,13-16}$ A good clinical result is not always related to complete healing of the meniscus in the area of the lesion, as demonstrated by Horibe et al. ${ }^{17}$ The author carried out second-look arthroscopy, evidencing $73 \%$ complete healing of the lesion, compared with $93 \%$ good clinical results. This data suggests that clinical success does not necessarily imply complete healing of the lesion. We did not propose to carry out postoperative arthroscopy in all the patients for research purposes, as it is an invasive procedure which, although relatively safe, can present complications, and also due to the fact that the majority of our patients obtained good clinical results. We carried out second-look arthroscopy only in one case due to persistence of symptoms. The patient presented hypersignal in the posterior horn of the medial meniscus in the MRI. During surgery, we observed that the meniscus was completely stable, without signs of meniscal lesion. Therefore, in cases where any symptoms persist, a correct evaluation of the status of the meniscus can avoid complications and unnecessary procedures. It also provides information to advise the patient of the level of activity that can be carried out following surgery.

The first studies using MRI after meniscal repair were described by Farley et $\mathrm{al}^{18}$ and Bronstein et al. ${ }^{19}$ These authors observe persistent alterations in signal in the area of the lesion, following meniscal suture. In many of these cases, the patients did not have clinical signs of failed healing or new rupture, and many were evaluated through arthroscopy, which demonstrated the presence of healing in the sutured area. The hypothesis proposed was that the persistent area of hypersignal in the region of the meniscal suture was due to the higher water content in the recent repair tissue..$^{20}$

Infiltration of the joint by the paramagnetic contrast can increase the sensitivity and specificity of the exam. In an experimental model using goats, Ritchie ${ }^{21}$ demonstrated the $100 \%$ accuracy of arthro-MRI for the evaluation of complete meniscal healing, compared with 33\% for conventional MRI. The diagnosis of a lesion or failed healing is done by visualizing the penetration of contrast medium at the site of the lesion.

The tomography associated with intrajoint infiltration of contrast (Arthro-CT) may be an alternative to Arthro-MRI. We have considered Arthro-CT particularly useful in cases where there is metallic synthesis material in the joint, to reduce the artefacts of the image presented in the MRI and Arthro-MRI, and also in cases where MRI 
is counterindicated, such as in patients with cardiac pacemakers, brain stents and cochlear implants. This study shows that Arthro-CT has the same effectiveness as Arthro-MRI for evidencing the penetration of contrast medium at the site of the meniscal suture, with the advantage that it is lower cost, more widely available and faster to perform than arthro-MRI.

\section{CONCLUSION}

Meniscal suture by the outside-in technique presented good or excellent results in $87.5 \%$ of our patients. Arthro-CT and arthro-MRI have equivalent accuracy for evidencing whether or not the sutured region of the meniscus had healed.

AUTHORS' CONTRIBUTIONS: Each author made significant individual contributions to this manuscript. AMDA (0000-0003-2507-3786)* and MUR (0000-0002-2020-9501)*: drafted the research project, conducted the surgeries, followed the patients, analyzed the data, and wrote the manuscript; MBR (0000-0003-4747-5081)*: evaluated the imaging, reviewed the literature, and drafted and revised the manuscript; AP (0000-0002-8449-7493)* and AH (0000-0001-8645-3956)*: contributed to the intellectual concept of the study and revised the manuscript. *ORCID (Open Researcher and Contributor ID).

\section{REFERENCES}

1. Arnoczky SP, Warren RF. Microvasculature of the human meniscus. Am J Sports Med. 1982;10(2):90-5.

2. Fairbank TJ. Knee joint changes after meniscectomy. J Bone Joint Surg Am. 1948;30B(4):664-70.

3. Annandale T. An operation for displaced semilunar cartilage. Br Med J 1885;1(1268):779.

4. King D. The healing of semilunar cartilages. Clin Orthop Relat Res. 1990;(252):4-7

5. Cannon WD Jr, Morgan CD. Meniscal repair: arthroscopic repair techniques. Instr Course Lect. 1994;43:77-96.

6. Cannon WD Jr. Arthroscopic meniscal repair. In: Insall JN, Scott WN, editors. Surgery of the Knee, $3^{\text {rd }}$ ed. Churchill-Livingstone, Philadelphia, Pennsylvannia; 2001. p.521-37.

7. Perdue PS Jr, Hummer CD $3^{\text {rd }}$, Colosimo AJ, Heidt RS Jr, Dormer SG. Meniscal repair: outcomes and clinical follow-up. Arthroscopy. 1996;12(6): 694-8.

8. Stone RG, Frewin MD, Gonzalez S. Long term assessment of arthroscopic meniscus repair: a two- to six-year follow-up study. Arthroscopy. 1990;6(2): 73-8.

9. Lysholm J, Gillquist J. Evaluation of knee ligament surgery results with special emphasis on use of a scoring scale. Am J Sports Med. 1982;10(3): 150-4

10. Irrgang JJ, Anderson AF, Boland AL, Harner CD, Kurosaka M, Neyret P et al. Development and validation of the International Knee Documentation Committee subjective knee form. Am J Sports Med. 2001;29(5):600-13.

11. Gill SS, Diduch DR. Outcomes after meniscal repair using the meniscus arrow in knees undergoing concurrent anterior cruciate ligament reconstruction. Arthroscopy. 2002;18(6):569-77.
12. Warren RF. Meniscectomy and repair in the anterior cruciate ligament-deficient patient. Clin Orthop. 1990;(252):55-63.

13. Cannon WD, Vittori JM. The incidence of healing in arthroscopic meniscal repairs in anterior cruciate ligament-reconstructed knees versus stable knees. Am J Sports Med.1992;20(2):176-81.

14. Asahina S, Muneta T, Yamamoto $\mathrm{H}$. Arthroscopic meniscal repair in conjunction with anterior cruciate ligament reconstruction: factors affecting the healing rate. Arthroscopy. 1996;12(5):541-45.

15. Steenbrugge F, Verdonk R, Verstraete K. Long term assessment of arthroscopic meniscus repair: a 13 year follow-up study. Knee. 2002;9(3):181-7.

16. Hanks GA, Gause TM, Handal JA, Kalenak A. Meniscus repair in the anterior cruciate deficient knee. Am J Sports Med. 1990;18(6):606-11.

17. Horibe S, Shino K, Maeda A, Nakamura N, Matsumoto N, Ochi T. Results of isolated meniscal repair evaluated by second look arthroscopy. Arthroscopy. 1996;12(2):150-5.

18. Farley TE, Howell SM, Love KF, Wolfe RD, Neumann CH. Meniscal tears: MR and arthrographic findings after arthroscopic repair. Radiology. 1991;180(2): 517-22.

19. Bronstein R, Kirk P, Hurley J. The usefulness of MRI in evaluating menisci after meniscus repair. Orthopedics. 1992;15(2):149-52.

20. Davis KW, Tuite MJ. MR imaging of the postoperative meniscus of the knee. Semin Musculoskelet Radiol. 2002;6(1):35-45.

21. Ritchie JR, Miller MD, Bents RT, Smith DK. Meniscal repair in the goat model. Am J Sports Med.1998;26(2):278-84 